\title{
ULLMANN, Sabine, Nachbarschaft und Konkurrenz. Juden und Christen in Dörfern der Markgrafschaft Burgau 1650 bis 1750
}

\section{Claire Gantet}

\section{(2) OpenEdition}

Édition électronique

URL : http://journals.openedition.org/ifha/1338

DOI : 10.4000/ifha. 1338

ISSN : 2198-8943

Éditeur

IFRA - Institut franco-allemand (sciences historiques et sociales)

Référence électronique

Claire Gantet, « ULLMANN, Sabine, Nachbarschaft und Konkurrenz. Juden und Christen in Dörfern der Markgrafschaft Burgau 1650 bis 1750 », Revue de l'IFHA [En ligne], Date de recension, mis en ligne le 01 janvier 2000, consulté le 22 septembre 2020. URL : http://journals.openedition.org/ifha/1338 ; DOI : https://doi.org/10.4000/ifha.1338

Ce document a été généré automatiquement le 22 septembre 2020.

(C)IFHA 


\title{
ULLMANN, Sabine, Nachbarschaft und Konkurrenz. Juden und Christen in Dörfern der Markgrafschaft Burgau 1650 bis 1750
}

\author{
Claire Gantet
}

1 Longtemps attachée à l'expulsion des Juifs hors des villes à la fin du Moyen Âge et aux violences de la période nazie, la recherche sur les Juifs s'est élargie depuis quelques années à l'époque moderne. Cette thèse, toutefois, à la différence des études menées sur la Hesse, le Brandebourg-Prusse et la chevalerie libre de Franconie, ne prend pas pour objet un territoire fermé enclosant des établissements juifs homogènes, mais la région morcelée du margraviat de Burgau en Souabe où se sont développées des communautés mixtes, chrétiennes et juives. Par là, cette étude, qui se revendique d'une analyse régionale menée d'un point de vue micro-historique, permet de jeter un regard bien plus fin sur les relations mal connues entre Juifs et Chrétiens. Elle s'étend sur un siècle, de 1650 et des efforts de peuplement qui suivent la guerre de Trente ans, jusqu'en 1750, c'est-à-dire avant les mesures d'émancipation, et s'articule en cinq chapitres qui envisagent successivement les conditions politiques et les cadres juridiques, les structures internes des communautés, les rapports économiques, la topographie et les relations sociales, et la coexistence au quotidien dans quatre villages.

2 L'existence et la structure de ces villages résulte des conflits entre la noblesse locale et l'Autriche Antérieure pour le contrôle des droits concédés aux Juifs (Judenschutz et Judenregal). La détention de ces prérogatives permet en effet non seulement de tirer des rentrées fiscales conséquentes mais aussi de s'affirmer face au rival politique. La base fragile et morcelée du margraviat de Burgau entrave toute juridiction d'ensemble et mène à des règlementations complexes et concurrentes. Tandis que du fait de l'appartenance du margraviat de Burgau à l'Autriche Antérieure et des entrées des plus grandes familles à la cour de Vienne, à Kriegshaber et Buttenwiesen, la protection 
impériale s'exerce à l'égard des Juifs, dans les villages médiats de Binswangen et Pfersee, les Juifs sont au contraire soumis à l'arbitraire de leurs maîtres locaux.

3 La structure économique ne recouvre pas les relations politiques. La concurrence interne entre les "villages juifs » entrâne une spécialisation commerciale. Ainsi Pfersee se concentre-t-il sur les relations de crédit avec Augsbourg, tandis que Kriegshaber privilégie le commerce des marchandises et du bétail avec les paysans des chapitres et de la principauté-évêché. L'analyse des contrats passés entre Juifs et Chrétiens ne révèle aucune prédilection sociale dans le cercle des clients; la grande majorité des actes concerne le petit commerce et contribue à lubrifier la circulation des biens entre la campagne et la ville. Des Chrétiens de tous les corps de métiers sont donc en contact durable avec les trafiquants juifs. Le commerce contribue néanmoins à hiérarchiser les "villages juifs ": ceux qui sont situés près de la ville et ont accès au marché urbain tirent des revenus bien plus lucratifs que les sites purement ruraux ; ces inégalités conduisent à maints conflits internes. Toutefois, la typologie villageoise fonctionnelle n'a pas d'incidence sur les formes de la coexistence entre Juifs et Chrétiens. Dans les quatre villages - au moyen d'un système qui n'est pas sans rappeler la parité introduite entre catholiques et luthériens dans quatre villes libres d'Empire en 1648 -, s'est mise en place une sorte de " communauté double » et d'administration dédoublée, tandis que les affaires générales se règlent en commun. Certes, la répartition des impôts, l'absence de ghetto et l'imbrication des topographies sacrées, les efforts menés par l'Église chrétienne pour monopoliser les lieux de cultes et cantonner le judaïsme dans la sphère privée mènent à maints conflits; des actes de violence sont parfois pratiqués contre des individus isolés et contre les lieux de culte. Mais au total, sur un siècle, on constate que la coexistence a été étonnamment supportable. Aucune bataille rangée n'a opposé les deux communautés, aussi peu homogènes l'une que l'autre, et les contacts commerciaux, les sociabilités quotidiennes et les solidarités l'ont emporté sur les préjugés. L'intérêt fiscal bien compris des autorités, mais aussi les conflits religieux eux-mêmes mènent, par leur caractère très ritualisé, à canaliser la violence.

4 À son terme, ce travail conduit à rejeter la thèse du caractère " marginal " des communautés juives postulé par l'historiographie. Étrangers dans le domaine religieux et dans de larges pans de la vie culturelle, Juifs et Chrétiens sont en situation concurrentielle pour le contrôle et l'exploitation des ressources, et vivent dans une symbiose conflictuelle mais étroite dans les champs de l'économie, de la politique communale et de la sociabilité. Cette thèse mène le lecteur donc à jeter un regard pondéré sur les communautés juives et leurs relations avec l'environnement chrétien, même s'il pourra regretter l'absence de perspective et de synthèse de ce travail très académique. 